Article

\title{
Do Loan Guarantees Alleviate Credit Rationing and Improve Economic Welfare?
}

\author{
Yu-Lin Wang ${ }^{1}$, Chien-Hui Lee ${ }^{2, *}$ and Po-Sheng Ko ${ }^{3, *}$ \\ 1 Department of Economics, National Chung Cheng University, Chiayi 621301, Taiwan; ecdylw@ccu.edu.tw \\ 2 Department of International Business, National Kaohsiung University of Science and Technology, \\ Kaohsiung 80778, Taiwan \\ 3 Department of Public Finance and Taxation, National Kaohsiung University of Science and Technology, \\ Kaohsiung 80778, Taiwan \\ * Correspondence: chlee@nkust.edu.tw (C.-H.L.); psko@nkust.edu.tw (P.-S.K.)
}

Received: 3 April 2020; Accepted: 4 May 2020; Published: 11 May 2020

check for updates

\begin{abstract}
By designing credit contracts with inversely related interest rates and collateral, banks can overcome the problems of adverse selection and moral hazard when there is an informational asymmetry in competitive credit markets. One salient result points out that, if borrowers' insufficient endowments of wealth cause a binding collateral constraint, a credit rationing equilibrium arises because of collateral's inability to achieve perfect sorting. The purpose of this paper is to examine the consequences of government loan guarantees on equilibrium credit contracts and economic welfare. More specifically, the effects of loan guarantees on interest rates, collateral, and credit rationing were studied. Our results suggest that government loan guarantees should target high-risk entrepreneurs. Loan guarantees targeting high-risk entrepreneurs reduce a pledge of collateral in credit contracts, drop social cost, and increase economic welfare. Under the circumstances that borrowers' insufficient wealth causes a binding collateral constraint, loan guarantees targeting high-risk entrepreneurs alleviate the problem of credit rationing and improve economic welfare.
\end{abstract}

Keywords: loan guarantees; collateral; credit rationing; economic welfare

\section{Introduction}

In a loan market, a lender provides funds and a borrower pays them back over time, plus additional interest payments that provide a return to the lender, and also represent the risk of the borrower defaulting on the loan. In general, lenders know less than borrowers about the risk of the loan. Lenders can offer a set of loan contracts with different combinations of interest rates and collateral to sort out borrowers of different riskiness [1,2]. However, if a borrower's wealth is insufficient to meet the collateral requirements, the borrower may face a possible chance of being denied credit [3]. Information asymmetry and insufficient collateral lead to credit rationing problems in the loan market.

To address whether the borrower's wealth is insufficient to meet the collateral requirements, many countries provide loan guarantee programs. Government loan guarantee programs have received new attention in response to the issue of credit rationing for small and medium enterprises (SMEs). Grimsby [4] pointed out that government loan guarantee programs were the most frequently applied measures, compared to the programs providing grants or tax credits, to enhance SMEs' liquidity during the financial crisis of 2008-2009. For example, the Italian government guarantee insures up to $80 \%$ of the value of a bank loan taken by SMEs, and the scheme has been quite effective in enhancing credit flows [5]. In the U.S., government-driven mortgage guarantee programs encourage lenders to provide mortgages for low-income and low-asset households [6]. In Spain, close to 99\% of all firms are SMEs; studying the impact of loan guarantee programs on firm performance is a promising topic [7]. However, 
within such a credit market of informational asymmetry and possible credit rationing equilibrium, what is the role of government loan guarantee programs on equilibrium credit contracts and economic welfare? This paper examines the effects of loan guarantee programs on the determination of the credit contracts, that is, the loan interest rates, the amount of collateral, and the probability of granting credit. It explores the comparative welfare properties of equilibrium without and with loan guarantees, and provides an answer to whom loan guarantees should target from the welfare perspectives.

As for a government loan guarantee program, government assures repayment to the lender for some fraction of a loan, should the borrower default. As such, a loan guarantee de-risks the loan for the lender. Reducing the risk for the lender changes a perspective loan in two possible ways. First, a lender may be willing to make a loan that he would have normally rejected without the guarantee. Second, as the interest rate of a loan reflects the perceived risk, a loan guarantee reduces the risk, thus reducing the interest rate and lowering the cost of the borrower's project. Riding et al. [8] pointed out that loan guarantee programs in Canada, France, and the UK are aimed to increase loanable funds to SMEs. Calcagnini et al. [9] examined the role of guarantees on loan interest rates of Italian firms and found that guarantees are more powerful for riskier borrowers than for safer borrowers, because they reduce larger interest rates for the former rather than for the latter. Pergelova and Angulo-Ruiz [10] used the data of new firms in the U.S. to examine the impact of government guarantees on firms' overall competitive advantage. The surge in loan guarantee programs prompts the following three questions: (1) should loan guarantee programs target to subside low-risk entrepreneurs or high-risk ones? (2) Can loan guarantee programs alleviate the problem of credit rationing? (3) Can loan guarantee programs improve economic welfare?

Informational asymmetry between lenders and borrowers about payoff-relevant borrower attributes usually leads to important implications of equilibrium contracts. In particular, the screening role of collateral is emphasized in a competitive credit market with asymmetric information. In agreement with Rothschild and Stiglitz [11] and Wilson [12], the optimal contract is a separating equilibrium. Collateral and interest rates constituting the contract are inversely related and effectively sort borrowers into different risk types. Taking the fact that most of the collateralizable assets are also productive resources, for example, physical capital and lands, whether or not collateral is required to pledge in loan contracts, potentially can affect production. Entrepreneurs who are required to provide collateral if they do not have enough collateralizable assets either face a nonzero fractional probability of being denied credit [3] or tend to overborrow loans and produce goods inefficiently [13]. A number of researchers empirically examine different aspects of asymmetric information in credit markets. For example, Best and Zhang [14] suggested that banks rely on other indicators as initial screening devices; thus, banks are not necessarily the unique information provider in an imperfect credit market. Hyytinen and Väänänen [15] found the origins of financial constraints faced by Finnish SMEs. Berndt and Gupta [16], using the U.S. data, investigated moral hazard and adverse selection problems of banks selling syndicated loans in the secondary market. Similarly, Ivashina [17] examined how the lead bank's ownership share of a syndicated loan affects the information asymmetry in the lending syndicate and measures the lead share's impact on the loan spread charged to the borrower. Jarrow [18] claimed that trading credit default swaps (CDSs) reduces debt market imperfections, facilitates a more optimal allocation of risks, and increases the traders' welfare.

Literature abounds about the implications of credit market inefficiency, with imperfect information also shedding light on some explicit forms of government intervention which would induce improvements upon market equilibrium. Smith and Stutzer [19] showed that loan guarantee programs issued through lenders and available to all borrowers have the effects of reducing all borrowers' interest rates and raising the probability of getting a loan for low-risk borrowers. Li [20,21] examined the effects of different government loan policies on the credit market with moral hazard, using a static model and a dynamic general equilibrium framework, respectively. Among the three loan policies, $\mathrm{Li}$ [20] concluded that loan guarantees attract relatively riskier borrowers than direct loans and grants do. So why are loan guarantees so popular? The reason may be simply because loan guarantees often 
do not appear in the budget until a payment is made, thus lessening the burden of tight government budgets. Chen [22] showed that collateral-based lending between banks and small-firm borrowers can lead to an inefficient liquidation problem, and loan guarantees provided by governments can alleviate this problem. Rai [23] incorporated government loan programs with cofinancing in a credit market characterized by a costly state verification problem and found that borrowers' welfare can be increased if government is the prior claimant. Minelli and Modica [24] found that loan guarantees amount to a price subsidy that induces the lender to loan out the optimal quantity of credit, and therefore, are efficient intervention. A recent paper of Gozzi and Schmukler [25] provided an overview of how loan guarantee schemes work around the world and presented a conceptual discussion of the role of government guarantee schemes in improving credit market inefficiency. Our paper follows this trend of discussion and provides an answer to the abovementioned three specific questions.

This paper introduces a government loan guarantee program into the economy of Besanko and Thakor [3] with an asymmetrically informative competitive credit market. Without any government intervention, low-risk borrowers choose contracts with low interest rates and high collateral requirements, whereas high-risk borrowers choose contracts with high interest rates and low collateral requirements. We examined the effects of loan guarantee programs on interest rates and collateral requirements and compared these effects between two loan guarantee programs: one is targeted at high-risk borrowers and the other is targeted at low-risk ones. Besanko and Thakor [3] also showed that the insufficient borrower wealth endowments may result in low-risk borrowers facing credit rationing. We then followed to study whether loan guarantee programs eliminate or alleviate the problem of credit rationing. Different from the conclusion in Besanko and Thakor [3] that the presence of a cosigner eliminates the possibility of rationing and always strictly improves borrower welfare, our results show whether a loan guarantee program increases economic welfare, depending on at whom the program is targeted.

The remainder of the paper proceeds as follows. Section 2 outlines the economic environment and the benchmark equilibrium, that is, the perfect information credit market equilibrium. Section 3 analyzes the effects of loan guarantee programs on credit market equilibrium when collateral constraints are not binding. Economic welfare is worse when loan guarantees target low-risk entrepreneurs rather than those without a loan guarantee program. However, loan guarantees targeting high-risk entrepreneurs reduce a pledge of collateral in credit contracts, lower social cost, and increase economic welfare. Section 4 emphasizes the effects of loan guarantees under a binding collateral constraint. The focus here is to elaborate the influence of loan guarantees on alleviating the problem of credit rationing. Section 5 provides a summary and conclusion.

\section{The Private Economy and a Benchmark}

The economy without government loan guarantees is similar to the model of Besanko and Thakor [3], with a competitive credit market where there is an informational asymmetry between borrowers and lenders. Building on Besanko and Thakor's conclusions of the sorting role of collateral and existence of credit rationing when collateral cannot achieve perfect sorting, our model further explores the effects on loan contracts and welfare implications of government loan guarantees. To motivate our analysis of this specific type of government intervention in a "potentially distorted" credit market, we first summarized the crucial features of Besanko and Thakor, then, we captured their important results into our framework of analysis [3].

Consider a universally risk-neutral economy in which each entrepreneur has an endowment $W$. In addition, an entrepreneur is endowed with one risky investment project which demands a fixed amount of goods as input, and will earn $G$ when the project succeeds and nothing when the project fails. The entrepreneur needs to borrow one unit of goods from a bank, add this to the initial endowment, and invest the total in the risky project. Alternatively, he can invest $W$ in a safe project and yield a constant return $b$, which represents an opportunity cost of undertaking the risky project. 
The bank faces a fixed pool of observationally identical borrowers consisting of two types, high-risk entrepreneurs and low-risk entrepreneurs. The probability that the risky project succeeds is $P_{1}$ for high-risk entrepreneurs and $P_{2}$ for low-risk entrepreneurs, $0<P_{1}<P_{2}<1$. When there is asymmetric information in the credit market, each borrower knows its own type, but the bank cannot distinguish among borrowers. The bank does know that a fraction $\lambda$ of these borrowers are high-risk types and that $(1-\lambda)$ are low-risk types. The loan contract $\Phi=\{r, C, \pi\}$ consists of the gross loan interest rate, the amount of collateral $C$, and the probability $\pi$ of granting a loan. On the other hand, with the fixed deposit gross interest rate $\gamma$, lenders are faced with perfect elastic deposit supply. Taking into account transaction costs resulted from taking possession of and liquidating collateral, the bank's valuation of collateral is $\beta C$, with $\beta \in(0,1)$, which is lower than the borrower's valuation of $C$.

The incremental expected utility of a type-i entrepreneur executing the risky project is:

$$
I_{i}=P_{i}\left(G-r_{i}\right)-\left(1-P_{i}\right) C_{i}-b \geq 0, i=1,2 .
$$

A bank's expected profit from lending to a type-i borrower is:

$$
B_{i}=P_{i} r_{i}+\left(1-P_{i}\right) \beta C_{i}-\gamma \geq 0, i=1,2 \text {. }
$$

In addition, we define economic welfare $E$ as the sum of the expectations (across states and types) of entrepreneur utility and bank profit. That is:

$$
E=\lambda \pi_{1}\left(I_{1}+B_{1}\right)+(1-\lambda) \pi_{2}\left(I_{2}+B_{2}\right)
$$

For simplicity, we assume that a borrower can apply to only one bank. The equilibrium loan contract is defined as among a set of loan contracts that earn non-negative profits for the bank, there exists one contract that maximizes an entrepreneur's (borrower's) expected returns.

\section{Equilibrium under Perfect Information}

To provide a benchmark, we first state the perfect information competitive equilibrium contract labeled by $\Phi_{i}^{*}=\left\{r_{i}^{*}, C_{i}^{*}, \pi_{i}^{*}\right\}$ and depict the chosen combination of interest rates and collateral for high-risk and low-risk entrepreneurs, respectively, in Figure 1.

$$
\Phi_{i}^{*}=\left\{r_{i}^{*}=\gamma P_{i}^{-1}, C_{i}^{*}=0, \pi_{i}^{*}=1, i=1,2\right\} .
$$

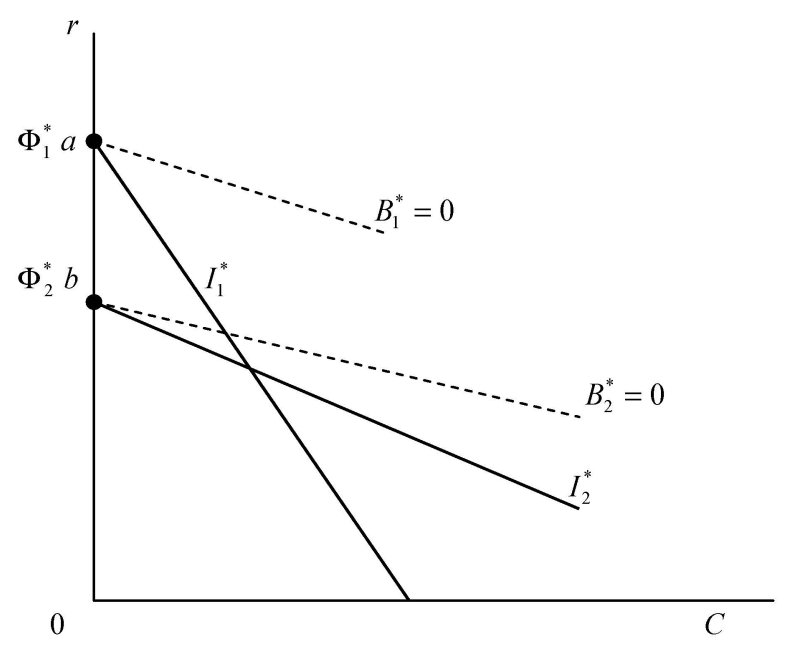

Figure 1. Equilibrium contract under perfect information. 
Under perfect information, the equilibrium loan contract maximizes an entrepreneur (borrower) $i$ 's expected utility subject to the constraint that the bank earns zero profits on that borrower. The loan contract under perfect information is depicted as $\Phi_{1}^{*}$ and $\Phi_{2}^{*}$ for high-risk and low-risk entrepreneurs, respectively, in Figure 1. At point $a, \Phi_{1}^{*}$ represents the combination of $C_{1}^{*}=0$ and $r_{1}^{*}=\gamma P_{1}^{-1}$, whereas at point $b, \Phi_{2}^{*}$ represents the combination of $C_{2}^{*}=0$, and $r_{2}^{*}=\gamma P_{2}^{-1}$. The expected utility line of high-risk entrepreneurs, $I_{1}^{*}$, is steeper than that of low-risk entrepreneurs, $I_{2}^{*}$. The line $B_{1}^{*}=0\left(B_{2}^{*}=0\right)$ represents banks' zero profits when they offer $\Phi_{1}^{*}\left(\Phi_{2}^{*}\right)$ to high-risk (low-risk) entrepreneurs.

Under perfect information, there is no role for collateral as signaling. In addition, for the sake of transaction cost, the collateral evaluation $(\beta C, 0<\beta<1)$ by the bank is lower than that of the entrepreneur who pledges the collateral. The collateral pledging is socially costly; thus, the optimal value of collateral requirements for entrepreneurs with whatever risk types, high or low, is equal to zero $\left(C_{1}^{*}=C_{2}^{*}=0\right)$. Both types of entrepreneurs receive the loan, and the interest rates charged for entrepreneurs with high risk is higher than that for entrepreneurs with low risk, $r_{1}^{*}>r_{2}^{*}$. The difference in interest rates simply reflects the fact that, under perfect competition, the borrowers receive the entire expected social surplus, and low-risk borrowers enjoy greater expected social surplus shown in the lower interest rate charged than high-risk borrowers do.

The first-best economic welfare $E^{*}$ under the benchmark is thus obtained by substituting the results of equilibrium contract $\Phi_{i}^{*}$ into Equations (1)-(3):

$$
E^{*}=\lambda\left(P_{1} G-b-\gamma\right)+(1-\lambda)\left(P_{2} G-b-\gamma\right)=\bar{P} G-b-\gamma,
$$

where $\bar{P} \equiv \lambda P_{1}+(1-\lambda) P_{2}$.

\section{Asymmetric Information and Government Loan Guarantees}

Consider a government loan guarantee program that guarantees a proportion $L$ of each private loan made by program-targeted entrepreneurs. In other words, the bank, in case of facing default, is guaranteed $L$ percent of the loan payment. To facilitate comparison, we assume that only one type of the entrepreneurs is the targeted group at a time. Assume that the government finances loan guarantees through imposition of a lump-sum tax. The government has access to the same information as the banks; therefore, under asymmetric information, each borrower knows its own type, but the bank and government cannot distinguish among borrowers. The bank and government know that a fraction $\lambda$ of these borrowers are high-risk types and that $(1-\lambda)$ are low-risk types. The information structure of including government loan guarantees into the model is shown in Figure 2.

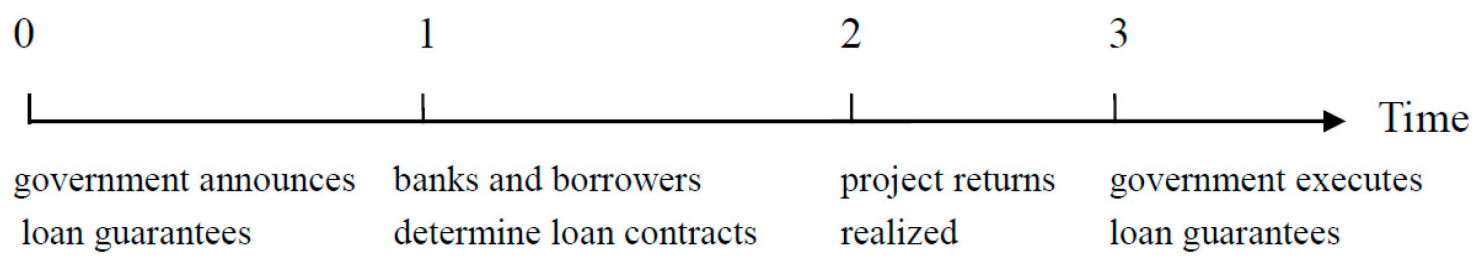

Figure 2. Information structure of government loan guarantees.

At first, government announces that at which risk type of entrepreneurs the loan guarantee program is targeted. Banks, taking the loan guarantees as consideration, determine the optimal loan contract with the borrowers. To make every borrower truthfully reveal their risk type, the loan contract requires meeting the condition of incentive compatibility. After entrepreneurs' project returns are realized, if the entrepreneurs cannot pay back the loan, the bank takes their collateral if it is pledged and collects the promised loan payment from the government if the loan is guaranteed.

Building on Besanko and Thakor's hints that, without any government credit policy [3], low-risk borrowers choose to pledge collateral, we first discuss the effects of loan guarantees targeting low-risk borrowers. Then we compare these effects when loan guarantees are targeted at high-risk ones. In both 
cases, we assume that borrowers' wealth is sufficient that the pledge of collateral does not constitute a binding constraint on them.

\subsection{Loan Guarantees Target Low-Risk Entrepreneurs}

When government announces it will guarantee $L$ percent of the loan payment for low-risk entrepreneurs, the zero-profit condition for the bank that makes a loan to low-risk borrowers becomes $P_{2} r_{2}+\left(1-P_{2}\right) \beta C_{2}+\left(1-P_{2}\right) L r_{2}=\gamma$. The first term $P_{2} r_{2}$ is the bank's gross interest revenues if the entrepreneur's project succeeds and pays back the debt. The next two terms, $\left(1-P_{2}\right) \beta C_{2}+$ $\left(1-P_{2}\right) L r_{2}$, describe that the bank receives collateral and guaranteed loan payment if the entrepreneur's project fails. Government financing this guarantee program needs to collect $T^{L}$ lump-sum taxes, $T^{L}=(1-\lambda) \pi_{2}\left(1-P_{2}\right) L r_{2}$, which equals multiplication of the proportion of low-risk borrowers, the probability of granting the loan, the probability of failure of the project, and the guaranteed loan payment.

The equilibrium contract $\Phi_{i}^{L}=\left\{\bar{r}_{i}^{L}, \bar{C}_{i}^{L}, \bar{\pi}_{i}^{L}, i=1,2\right\}$ solves the following problem (We label the equilibrium contract under asymmetric information and unbinding collateral constraints as $\bar{\Phi}$; and adding a subscript $L, \bar{\Phi}^{L}$, express there are loan guarantees targeted at low-risk borrowers.):

$$
\operatorname{Max} . \lambda \pi_{1} I_{1}+(1-\lambda) \pi_{2} I_{2}
$$

s.t.

$$
\begin{gathered}
\pi_{1}\left\{P_{1}\left(G-r_{1}\right)-\left(1-P_{1}\right) C_{1}-b\right\} \geq \pi_{2}\left\{P_{1}\left(G-r_{2}\right)-\left(1-P_{1}\right) C_{2}-b\right\} \\
\pi_{2}\left\{P_{2}\left(G-r_{2}\right)-\left(1-P_{2}\right) C_{2}-b\right\} \geq \pi_{1}\left\{P_{2}\left(G-r_{1}\right)-\left(1-P_{2}\right) C_{1}-b\right\} \\
0 \leq \pi_{i} \leq 1, i=1,2 \\
0 \leq C_{i} \leq W, i=1,2 \\
P_{1} r_{1}+\left(1-P_{1}\right) \beta C_{1}=\gamma \\
P_{2} r_{2}+\left(1-P_{2}\right) \beta C_{2}+\left(1-P_{2}\right) L r_{2}=\gamma
\end{gathered}
$$

Equations (5a) and (5b) are the incentive compatibility constraints. With asymmetric information, the optimal loan contract obtained under perfect information, $\Phi_{i}^{*}=\left\{r_{i}^{*}, C_{i}^{*}, \pi_{i}^{*}, i=1,2\right\}$, cannot satisfy the incentive compatibility constraints. The reason is that, under perfect information, no collateral is required for either type of borrowers, and high-risk borrowers are charged a higher interest rate, causing them to have an incentive to disguise themselves as low-risk ones. The bank's contract must, therefore, satisfy these incentive compatibility constraints. Equations (6) and (7) are feasibility conditions. Equation (8a) is the bank's zero-profit condition when it loans to high-risk borrowers, whereas Equation ( $8 \mathrm{~b})$ is the similar condition when the bank loans to low-risk borrowers who are included in loan guarantees.

The solution of this contract is as below:

$$
\begin{gathered}
\bar{r}_{1}^{L}=\gamma P_{1}^{-1}, \quad \bar{C}_{1}^{L}=0, \quad \bar{\pi}_{1}^{L}=1, \\
\bar{r}_{2}^{L}=\frac{\gamma-\left(1-P_{2}\right) \beta \bar{C}_{2}^{L}}{P_{2}+\left(1-P_{2}\right) L}, \quad \bar{C}_{2}^{L}=\frac{\gamma\left[\left(P_{2}-P_{1}\right)+\left(1-P_{2}\right) L\right]}{\left[P_{2}\left(1-P_{1}\right)+P_{1}\left(1-P_{2}\right) \beta\right]+\left(1-P_{2}\right)\left(1-P_{1}\right) L}, \quad \bar{\pi}_{2}^{L}=1 .
\end{gathered}
$$

Obviously, without loan guarantees, $L=0$, the equilibrium contract under asymmetric information and unbinding collateral constraints is the same as the one in Besanko and Thakor [3], denoted by $\bar{\Phi}_{i}=\left\{\bar{r}_{i}, \bar{C}_{i}, \bar{\pi}_{i}, i=1,2\right\}$ and depicted in Figure 3. The separating equilibrium consists of two contracts: 
one is located at point $a$ chosen by high-risk borrowers, and the other is located at point $\bar{c}$ chosen by low-risk borrowers.

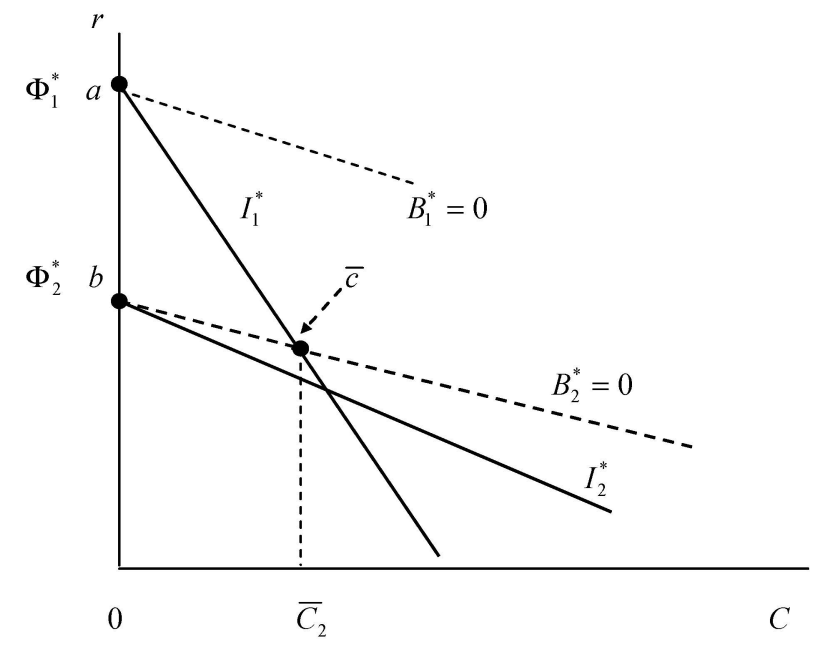

Figure 3. Without loan guarantees: unbinding collateral constraints.

However, when loan guarantees are targeted at low-risk borrowers, the bank's zero-profit condition, which includes guaranteed loan payment from government, implies that low-risk borrowers can retain greater expected social surplus than they can without government loan guarantees. This can be shown from the inward movement of line $B_{2}^{*}=0$ to $B_{2}^{L}=0$ and low-risk borrowers' expected utility line $I_{2}^{*}$ to $I_{2}^{L}$ in Figure 4. Low-risk borrowers take the contract at point $c^{L}$ instead of point $\bar{c}$, pledging more collateral in exchange for a lower interest rate. Not surprisingly, high-risk borrowers choose the same contract as the one without a government loan program.

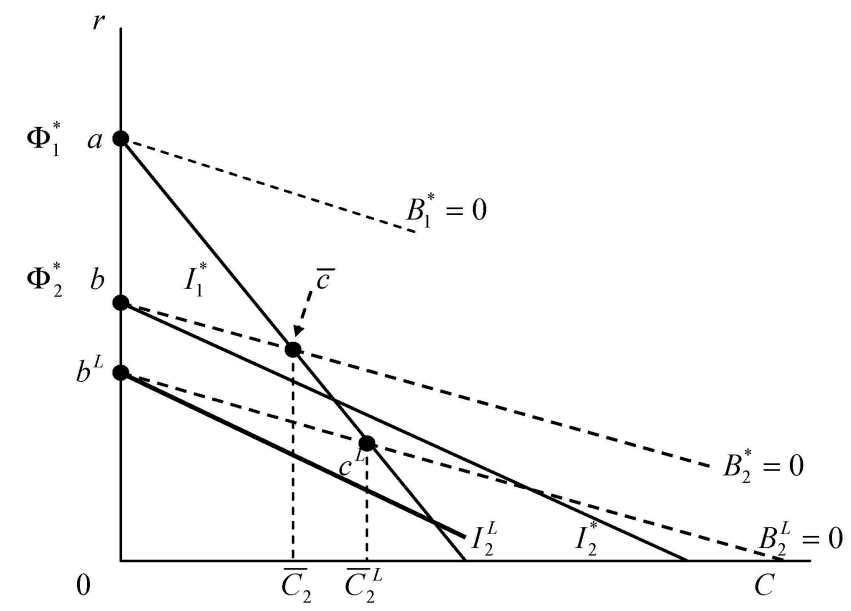

Figure 4. Loan guarantees targeting low-risk types: unbinding collateral constraints.

Lemma 1. With unbinding collateral constraints, loan guarantees targeting low-risk entrepreneurs increase the amount of collateral $\left(\bar{C}_{2}^{L}>\bar{C}_{2}\right)$ and reduce the interest rate $\left(\bar{r}_{2}^{L}<\bar{r}_{2}\right)$ for low-risk entrepreneurs in equilibrium contract.

Proof. $L=0, \bar{C}_{2}^{L}=\bar{C}_{2} . d \bar{C}_{2}^{L} / d L>0, \bar{C}_{2}^{L}>\bar{C}_{2}, \forall L>0 . L=0, \bar{r}_{2}^{L}=\bar{r}_{2} . d \bar{r}_{2}^{L} / d L<0, \bar{r}_{2}^{L}<\bar{r}_{2}, \forall L>0$. 
Lemma 1 shows that the amount of collateral pledged by low-risk borrowers, $\bar{C}_{2}^{L}$, is increasing with the $L$ percent of loan guarantees, and the interest rate charged for low-risk borrowers, $\bar{r}_{2}^{L}$, is decreasing with $L$; thus, compared with $\left(\bar{C}_{2}, \bar{r}_{2}\right)$ in the absence of loan guarantees, $\bar{C}_{2}^{L}>\bar{C}_{2}$ and $\bar{r}_{2}^{L}<\bar{r}_{2}$.

Under asymmetric information, interest rates alone cannot sort out borrowers of different risk types; collateral requirements serve as an incentive mechanism. Without government credit policy, low-risk borrowers have pledged collateral in exchange for a lower interest rate than that under perfect information. With loan guarantees that make a further lower interest rate possible, the incentive of pledging more collateral becomes even stronger. As long as their wealth is sufficient to pledge collateral, the loan is granted with a lower interest rate.

The social welfare under the economy with loan guarantees targeting low-risk entrepreneurs is labeled as $\bar{E}^{L}$ and is obtained by summation of the expected entrepreneur utility and bank profit, subtracting the cost of the loan guarantee program, $T^{L}$. That is,

$$
\bar{E}^{L}=\lambda \bar{\pi}_{1}^{L}\left(\bar{I}_{1}^{L}+\bar{B}_{1}^{L}\right)+(1-\lambda) \bar{\pi}_{2}^{L}\left(\bar{I}_{2}^{L}+\bar{B}_{2}^{L}\right)-T^{L}
$$

Substituting the results of equilibrium contract $\bar{\Phi}^{L}$ into Equation (9), we obtain:

$$
\bar{E}^{L}=\bar{P} G-b-\gamma-(1-\lambda)\left(1-P_{2}\right)(1-\beta) \bar{C}_{2}^{L}
$$

Similarly, the economic welfare without loan guarantees is calculated using the contract $\bar{\Phi}_{i}$

$$
\bar{E}=\bar{P} G-b-\gamma-(1-\lambda)\left(1-P_{2}\right)(1-\beta) \bar{C}_{2}
$$

Compare economic welfare with loan guarantees targeting low-risk borrowers, $\bar{E}^{L}$, and that without loan guarantees, $\bar{E}$, i.e., Equations (10) and (11):

$$
\bar{E}^{L}-\bar{E}=(1-\lambda)(1-\beta)\left(1-P_{2}\right)\left(\bar{C}_{2}-\bar{C}_{2}^{L}\right)<0
$$

In addition, we also know:

$$
\bar{I}_{1}^{L}-\bar{I}_{1}=0, \quad \text { and } \quad \bar{I}_{2}^{L}-\bar{I}_{2}=P_{2}\left(\bar{r}_{2}-\bar{r}_{2}^{L}\right)+\left(1-P_{2}\right)\left(\bar{C}_{2}-\bar{C}_{2}^{L}\right)>0
$$

Proposition 1 summarizes these results of welfare comparison.

Proposition 1. With unbinding collateral constraints, loan guarantees targeting low-risk entrepreneurs increase these entrepreneurs' utilities and leave high-risk entrepreneurs' utilities the same. Moreover, this loan guarantee scheme decreases overall economic welfare.

The reason that loan guarantees reduce the overall economic welfare is attributed to their raising of collateral. Pledging collateral is socially costly because of its lower valuation by banks than by entrepreneurs.

\subsection{Loan Guarantees Target High-Risk Entrepreneurs}

This section turns to the discussion about the effects of loan guarantees if the targeted group that government chooses to assist is the high-risk type of borrowers. From Proposition 1, loan guarantees targeting low-risk borrowers are harmful to the overall economic welfare because they deteriorate asymmetric information problems in the credit market. Low-risk borrowers are forced to pledge more collateral than they ever did to sort themselves out from high-risk borrowers and deter high-risk borrowers from disguising themselves as low-risk ones. Loan guarantees, however, increase a targeted group's welfare, resulting in putting up too much collateral at a cost of reducing overall economic welfare. 
Can loan guarantees targeting the other type of borrowers remedy their dilemma on distributive and overall welfare effects?

When loan guarantees target high-risk entrepreneurs, government guarantees $L$ percent of their loan payment, and the zero-profit condition for the bank that makes a loan to high-risk borrowers becomes $P_{1} r_{1}+\left(1-P_{1}\right) \beta C_{1}+\left(1-P_{1}\right) L r_{1}=\gamma$. Similarly, assume that the government finances loan guarantees by collecting $T^{H}$ lump-sum taxes, $T^{H}=\lambda \pi_{1}\left(1-P_{1}\right) L r_{1}$. The economic welfare associated with this loan program, $\bar{E}^{H}$, is thus expressed as follows:

$$
\bar{E}^{H}=\lambda \bar{\pi}_{1}^{H}\left(\bar{I}_{1}^{H}+\bar{B}_{1}^{H}\right)+(1-\lambda) \bar{\pi}_{2}^{H}\left(\bar{I}_{2}^{H}+\bar{B}_{2}^{H}\right)-T^{H}
$$

The equilibrium contract is similarly derived as that in Section 3.1, except by replacing Equations (8a) and (8b) with the following two Equations.

$$
\begin{gathered}
P_{1} r_{1}+\left(1-P_{1}\right) \beta C_{1}+\left(1-P_{1}\right) L r_{1}=\gamma \\
P_{2} r_{2}+\left(1-P_{2}\right) \beta C_{2}=\gamma
\end{gathered}
$$

We denote the equilibrium contract when loan guarantees targeting high-risk borrowers as $\bar{\Phi}_{i}^{H}=\left\{\bar{r}_{i}^{H}, \bar{C}_{i}^{H}, \bar{\pi}_{i}^{H}, i=1,2\right\}$. The solution of this contract is as below:

$$
\begin{gathered}
\bar{r}_{1}^{H}=\frac{\gamma}{P_{1}+\left(1-P_{1}\right) L}, \quad \bar{C}_{1}^{H}=0, \quad \bar{\pi}_{1}^{H}=1, \\
\bar{r}_{2}^{H}=\frac{\gamma-\left(1-P_{2}\right) \beta \bar{C}_{2}^{H}}{P_{2}}, \quad \bar{C}_{2}^{H}=\frac{\gamma P_{1}\left[\frac{P_{2}}{L\left(1-P_{1}\right)+P_{1}}-1\right]}{P_{2}\left(1-P_{1}\right)-P_{1}\left(1-P_{2}\right) \beta}, \quad \bar{\pi}_{2}^{H}=1 .
\end{gathered}
$$

Again, without loan guarantees, $L=0$, the equilibrium contract under asymmetric information and unbinding collateral constraints is the same as the one in Besanko and Thakor [3], labeled by $\bar{\Phi}_{i}=\left\{\bar{r}_{i}, \bar{C}_{i}, \bar{\pi}_{i}, i=1,2\right\}$ and depicted in Figure 3. When loan guarantees are targeted at high-risk borrowers, the bank's zero-profit condition implies that high-risk borrowers can retain greater expected social surplus than they can without government loan guarantees. This can be shown from the inward movement of line $B_{1}^{*}=0$ to $B_{1}^{H}=0$ and high-risk borrowers' expected utility line $I_{1}^{*}$ to $I_{1}^{H}$ in Figure 5 . Low-risk borrowers take the contract at point $c^{H}$ instead of point $\bar{c}$, pledging less collateral than they do without a government loan program. For high-risk borrowers who can apply loan guarantees, they pay less interest and still do not pledge any collateral.

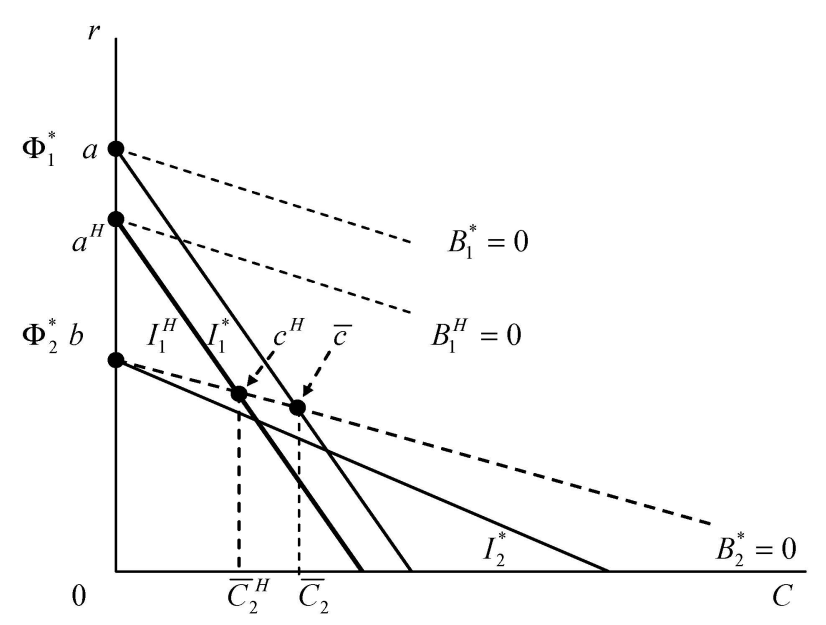

Figure 5. Loan guarantees targeting high-risk types: unbinding collateral constraints. 
Lemma 2. With unbinding collateral constraints, loan guarantees targeting high-risk entrepreneurs decrease the amount of collateral $\left(\bar{C}_{2}^{H}<\bar{C}_{2}\right)$ and increase the interest rate $\left(\bar{r}_{2}^{H}>\bar{r}_{2}\right)$ for low-risk entrepreneurs in equilibrium contract. The targeted high-risk entrepreneurs pay less interest $\left(\bar{r}_{1}^{H}<\bar{r}_{1}\right)$ and pledge no collateral $\left(\bar{C}_{1}^{H}=0\right)$.

Proof. $L=0, \bar{C}_{2}^{H}=\bar{C}_{2} \cdot d \bar{C}_{2}^{H} / d L<0, \bar{C}_{2}^{H}<\bar{C}_{2}, \forall L>0$.

$$
\begin{aligned}
& L=0, \bar{r}_{2}^{H}=\bar{r}_{2} \cdot d \bar{r}_{2}^{H} / d L>0, \bar{r}_{2}^{H}>\bar{r}_{2}, \forall L>0 . \\
& L=0, \bar{r}_{1}^{H}=\bar{r}_{1} \cdot d \bar{r}_{1}^{H} / d L<0, \bar{r}_{1}^{H}<\bar{r}_{1}, \forall L>0 .
\end{aligned}
$$

Lemma 2 shows that when loan guarantees target high-risk entrepreneurs, the amount of collateral pledged by low-risk borrowers, $\bar{C}_{2}^{H}$, is decreasing with the $L$ percent of loan guarantees; the interest rate charged for low-risk borrowers, $\bar{r}_{2}^{H}$, is increasing with $L$; and the interest rate charged for high-risk borrowers, $\bar{r}_{1}^{H}$, is decreasing with $L$. Thus, compared with $\left(\bar{C}_{2}, \bar{r}_{2}\right)$ in the absence of loan guarantees, $\bar{C}_{2}^{H}<\bar{C}_{2}$ and $\bar{r}_{2}^{H}>\bar{r}_{2}$, and the targeted high-risk entrepreneurs pay less interest $\left(\bar{r}_{1}^{H}<\bar{r}_{1}\right)$.

When high-risk borrowers are the targeted group for loan guarantees, banks offer them a lower interest rate, mitigating the problem of misrepresenting themselves as low-risk borrowers. Thus, the role of collateral as a signaling device for deterring high-risk borrowers from choosing a low-risk borrowers' contract is not as important as that in Section 3.1 and that without government loan guarantees. Aside from interest rate and collateral, both types of borrowers are granted credit because of their sufficient wealth to pledging collateral.

The economic welfare when loan guarantees target high-risk entrepreneurs, $\bar{E}^{H}$, is obtained by substituting the results of equilibrium contract $\bar{\Phi}_{i}^{H}$ into Equation (12):

$$
\bar{E}^{H}=\bar{P} G-b-\gamma-(1-\lambda)\left(1-P_{2}\right)(1-\beta) \bar{C}_{2}^{H}
$$

Compare Equation (14) with the economic welfare without loan guarantees $\bar{E}$ in Equation (11) to have:

$$
\bar{E}^{H}-\bar{E}=(1-\lambda)\left(1-P_{2}\right)(1-\beta)\left(\bar{C}_{2}-\bar{C}_{2}^{H}\right)>0
$$

In addition, the following comparison holds, which leads us to Proposition 2.

$$
\begin{array}{cl} 
& \bar{I}_{1}^{H}-\bar{I}_{1}=-P_{1}\left(\bar{r}_{1}^{H}-\bar{r}_{1}\right)>0 \\
\bar{I}_{2}^{H}-\bar{I}_{2}=-\left(1-P_{2}\right)\left(\bar{C}_{2}^{H}-\bar{C}_{2}\right)-P_{2}\left(\bar{r}_{2}^{H}-\bar{r}_{2}\right) \\
=\frac{L(1-\beta) \gamma\left(1-P_{1}\right)\left(1-P_{2}\right) P_{2}}{\left[L\left(1-P_{1}\right)+P_{1}\right]\left\{P_{2}\left(1-P_{1}\right)-P_{1}\left(1-P_{2}\right) \beta\right\}}>0
\end{array}
$$

Proposition 2. With unbinding collateral constraints, loan guarantees targeting high-risk entrepreneurs increase both types of entrepreneurs' utilities, as well as overall economic welfare.

Loan guarantees targeting high-risk entrepreneurs are Pareto improving in the sense that they increase overall economic welfare. The reason that loan guarantees improve welfare lies in their effectively reducing the amount of collateral pledged. Even if collateral plays a screening role in the imperfectly informational credit market, pledging collateral is socially costly. With a loan guarantee program carefully designed to target high-risk borrowers, it cures partial imperfect information, and therefore increases the efficiency of the credit market.

\section{Binding Collateral Constraints}

If the entrepreneur does not have sufficient wealth to provide collateral, the collateral constraint then turns out to be binding. In this case, if there is no government loan program, the equilibrium contract sets $\bar{C}_{2}=W$. Because the collateral needed for self-selection exceeds $W$, a collateral requirement 
of $W$ is insufficient to deter high-risk borrowers from choosing the low-risk contract. Banks respond to this incentive compatibility problem by reducing the probability of extending credit to a low-risk borrower; thus, rationing exists even with collateral.

We depict the result of equilibrium contract when $W$ imposes binding constraint on collateral in Figure 6. The noteworthy feature of this contract labeled as $\hat{\Phi}_{i}=\left\{\hat{r}_{i}, \hat{C}_{i}, \hat{\pi}_{i}, i=1,2\right\}$ is that low-risk borrowers face some likelihood of being explicitly denied credit even though the bank's supply of loanable funds is unconstrained.

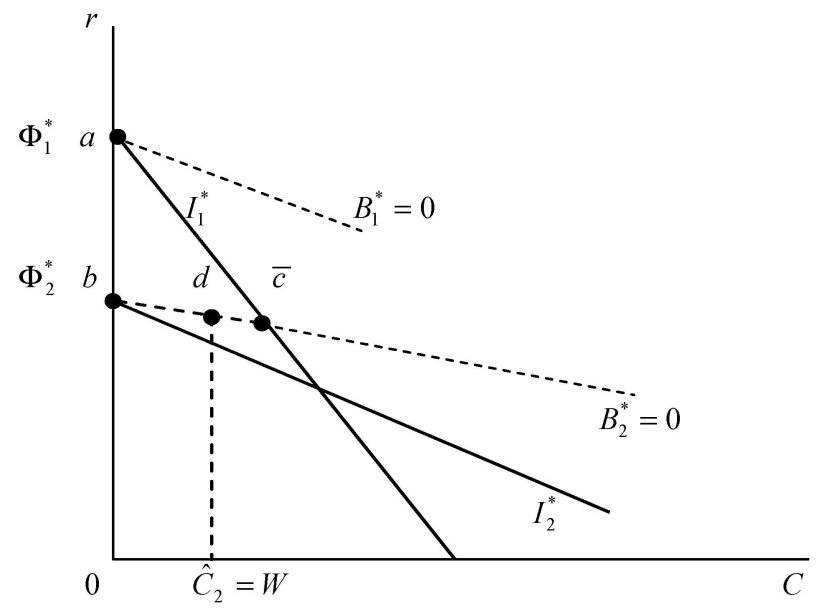

Figure 6. Without loan guarantees: binding collateral constraints.

Corollary 1. (Proposition 3 of Besanko and Thakor [3]) If $W<\frac{\gamma\left(P_{2}-P_{1}\right)}{P_{2}\left(1-P_{1}\right)-P_{1}\left(1-P_{2}\right) \beta}$, then the Nash equilibrium under asymmetric information is given by:

$$
\begin{aligned}
& \hat{r}_{1}=\gamma P_{1}^{-1}, \hat{C}_{1}=0, \hat{\pi}_{1}=1 . \\
& \hat{r}_{2}=\frac{\gamma-\left(1-P_{2}\right) \beta W}{P_{2}}, \hat{C}_{2}=W, \hat{\pi}_{2}=\frac{P_{1} G-b-\gamma}{P_{1}\left[G-\frac{\gamma-\left(1-P_{2}\right) \beta W}{P_{2}}\right]-\left(1-P_{1}\right) W-b} .
\end{aligned}
$$

It is assumed that $\beta / P_{2}>\left(1-P_{1}\right) /\left(1-P_{2}\right)$, and $\hat{\pi}_{2}<1$.

The economic welfare under a binding collateral constraint is similarly derived as:

$$
\hat{E}=\lambda\left\{P_{1} G-b-\gamma\right\}+(1-\lambda) \hat{\pi}_{2}\left\{P_{2} G-\left(1-P_{2}\right)(1-\beta) W-b-\gamma\right\}
$$

Comparing this economic welfare with the one without a binding effect on collateral, Equation (11), we obtain:

$$
\hat{E}-\bar{E}=(1-\lambda) \hat{\pi}_{2}\left\{\begin{array}{c}
P_{2} G-\left(1-P_{2}\right)(1-\beta) W \\
-b-\gamma
\end{array}\right\}-(1-\lambda) \bar{\pi}_{2}\left\{\begin{array}{c}
P_{2} G-\left(1-P_{2}\right)(1-\beta) C_{2} \\
-b-\gamma
\end{array}\right\}<0
$$

High-risk borrowers take the same contract regardless of whether collateral constraints are binding or not. Their expected utilities are the same in either case. However, low-risk borrowers are those who face the problem of insufficient wealth to pledging collateral, and are credit-rationed even more severely than they were without a binding constraint. The expected utilities of low-risk borrowers are reduced, as is the overall economic welfare in this binding constraint case.

Under these circumstances, we ask whether economic welfare will be improved if loan guarantees target low-risk borrowers. 


\subsection{Loan Guarantees Target Low-Risk Entrepreneurs}

We depict the equilibrium contract under a binding collateral constraint, $C_{2}=W$, and loan guarantees targeting low-risk borrowers in Figure 7 and denote the contract as $\hat{\Phi}_{i}^{L}=\left\{\hat{r}_{i}^{L}, \hat{C}_{i}^{L}, \hat{\pi}_{i}^{L}, i=1,2\right\}$. The solution of this contract is as below:

$$
\begin{aligned}
& \hat{r}_{1}^{L}=\gamma P_{1}^{-1}, \quad \hat{C}_{1}^{L}=0, \quad \hat{\pi}_{1}^{L}=1, \\
& \hat{r}_{2}^{L}=\frac{\gamma-\left(1-P_{2}\right) \beta W}{P_{2}+\left(1-P_{2}\right) L}, \quad \hat{C}_{2}^{L}=W, \quad \hat{\pi}_{2}^{L}=\frac{P_{1} G-b-\gamma}{P_{1}\left[G-\frac{\gamma-\left(1-P_{2}\right) \beta W}{L\left(1-P_{2}\right)+P_{2}}\right]-\left(1-P_{1}\right) W-b} .
\end{aligned}
$$

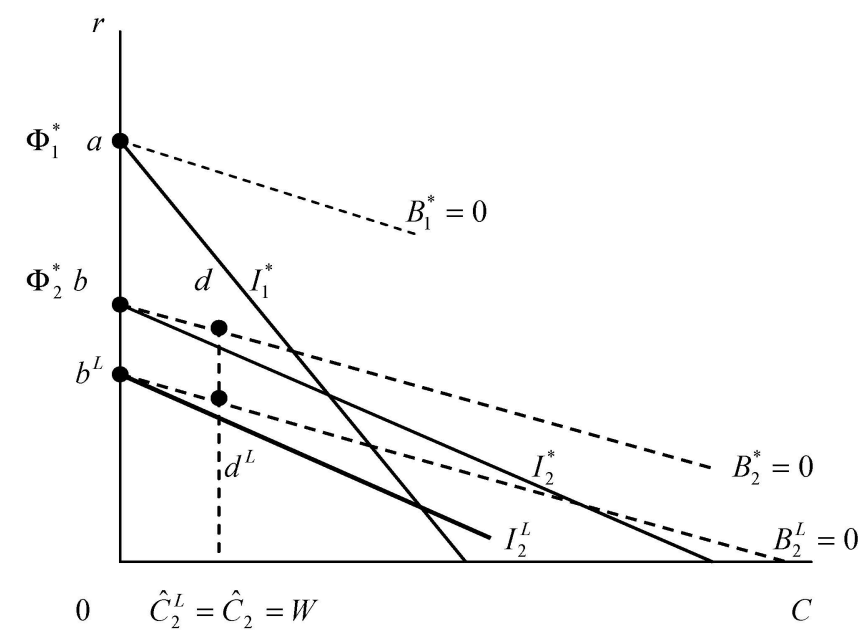

Figure 7. Loan guarantees targeting low-risk types: binding collateral constraints.

Lemma 3. Loan guarantees targeting low-risk entrepreneurs who face a binding collateral constraint will lower their probability of granting the loan.

Proof. $L=0, \hat{\pi}_{2}^{L}=\hat{\pi}_{2} . d \hat{\pi}_{2}^{L} / d L<0, \hat{\pi}_{2}^{L}<\hat{\pi}_{2}, \forall L>0$.

Obviously, the probability of granting the loan for low-risk borrowers is decreasing with the $L$ percent of loan guarantees. Lemma 3 shows that, when low-risk entrepreneurs do not have sufficient wealth to provide collateral, they face an even greater severe credit rationing situation with government guarantees than without it. Under the contract, $\hat{\Phi}_{i}^{L}=\left\{\hat{r}_{i}^{L}, \hat{C}_{i}^{L}, \hat{\pi}_{i}^{L}, i=1,2\right\}$, we calculate economic welfare when loan guarantees target low-risk borrowers who face a binding collateral constraint:

$$
\hat{E}^{L}=\lambda\left\{P_{1} G-b-\gamma\right\}+(1-\lambda) \hat{\pi}_{2}^{L}\left\{P_{2} G-b-\gamma-\left(1-P_{2}\right)(1-\beta) W\right\}
$$

Compare economic welfare with and without loan guarantees, that is, compare Equations (15) and (16):

$$
\begin{gathered}
\hat{E}^{L}-\hat{E}=(1-\lambda)\left(\hat{\pi}_{2}^{L}-\hat{\pi}_{2}\right)\left\{P_{2} G-\left(1-P_{2}\right)(1-\beta) W-b-\gamma\right\}<0, \\
\text { if } G>\left[\left(1-P_{2}\right)(1-\beta) W-b-\gamma\right] / P_{2} .
\end{gathered}
$$

Proposition 3. If the returns of the risky project succeeds are big enough, $G>\left[\left(1-P_{2}\right)(1-\beta) W-b-\gamma\right] / P_{2}$. Loan guarantees targeting low-risk entrepreneurs who face a binding collateral constraint deteriorate credit rationing and reduce overall economic welfare.

With loan guarantees, banks charge a lower interest rate to low-risk borrowers at a cost of requiring more collateral. However, if low-risk borrowers' wealth is insufficient to pledging collateral, they are rationed even more severely in the credit market than they are without loan guarantees. 


\subsection{Loan Guarantees Target High-Risk Entrepreneurs}

When loan guarantees target high-risk entrepreneurs under the circumstances that entrepreneurs' wealth is insufficient to pledge collateral, the equilibrium contract is shown below and depicted in Figure 8.

$$
\begin{aligned}
& \hat{r}_{1}^{H}=\frac{\gamma}{P_{1}+\left(1-P_{1}\right) L}, \hat{C}_{1}^{H}=0, \hat{\pi}_{1}^{H}=1, \\
& \hat{r}_{2}^{H}=\frac{\gamma-\left(1-P_{2}\right) \beta \hat{C}_{2}^{H}}{P_{2}}, \hat{C}_{2}^{H}=W, \\
& \hat{r}_{2}^{H}=\frac{P_{1} G-b-\frac{P_{1} \gamma}{L\left(1-P_{1}\right)+P_{1}}}{P_{1}\left[G-\frac{\gamma-\left(1-P_{2}\right) \beta W}{P_{2}}\right]-\left(1-P_{1}\right) W-b} . \\
& \text { If } \beta>\frac{\gamma P_{1}\left[L\left(1-P_{1}\right)+P_{1}\right]+\left\{L W+P_{1}\left[W-2 L W-\gamma-(1-L) W P_{1}\right]\right] P_{2}}{W P_{1}\left[L\left(1-P_{1}\right)+P_{1}\right]\left(1-P_{2}\right)}, \text { then } \hat{\pi}_{2}^{H}<1 .
\end{aligned}
$$

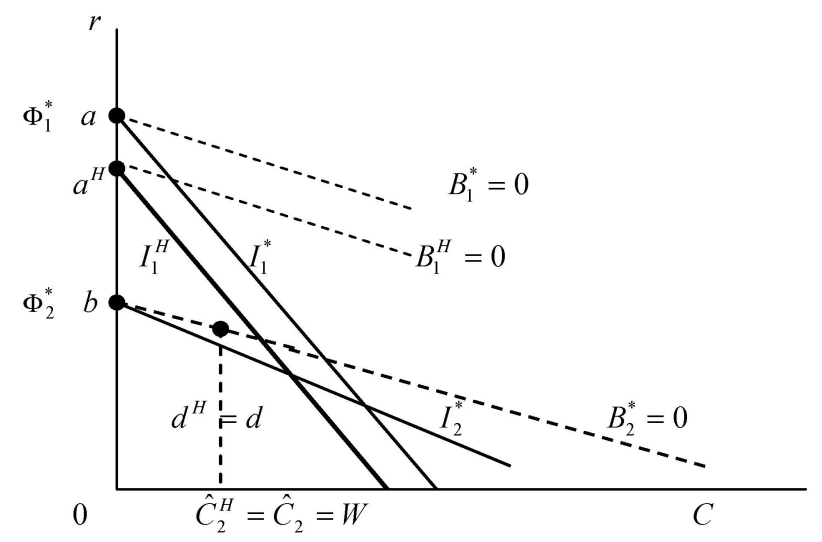

Figure 8. Loan guarantees targeting high-risk types: binding collateral constraints.

Lemma 4. Loan guarantees targeting high-risk entrepreneurs will raise the probability of granting the loan for low-risk entrepreneurs who face a binding collateral constraint.

Proof. $L=0, \hat{\pi}_{2}^{H}=\hat{\pi}_{2} \cdot d \hat{\pi}_{2}^{H} / d L>0, \hat{\pi}_{2}^{H}>\hat{\pi}_{2}, \forall L>0$.

Now, the probability of granting the loan for low-risk borrowers is increasing with the L percent of loan guarantees. Lemma 4 shows that when loan guarantees target high-risk entrepreneurs and low-risk entrepreneurs face binding collateral constraints, this loan guarantee scheme indeed loosens low-risk entrepreneurs' credit rationing. When high-risk borrowers are the targeted group for loan guarantees, banks offer them a lower interest rate, easing the incentive compatibility constraint with which they should abide. This was supposed to be shown, in part, by the reduction of low-risk borrowers' collateral pledge. However, if low-risk borrowers' wealth is insufficient so that collateral constraint is binding, this intention should be shown by increasing the chance of granting credit for low-risk borrowers.

Using the contract, $\hat{\Phi}_{i}^{H}=\left\{\hat{r}_{i}^{H}, \hat{C}_{i}^{H}, \hat{\pi}_{i}^{H}, i=1,2\right\}$, we calculate economic welfare when loan guarantees target high-risk borrowers:

$$
\hat{E}^{H}=\lambda\left\{P_{1} G-b-\gamma\right\}+(1-\lambda) \hat{\pi}_{2}^{H}\left\{P_{2} G-\left(1-P_{2}\right)(1-\beta) W-b-\gamma\right\}
$$

Compare economic welfare with and without loan guarantees, that is, compare Equations (15) and (17):

$$
\hat{E}^{H}-\hat{E}=(1-\lambda)\left(\hat{\pi}_{2}^{H}-\hat{\pi}_{2}\right)\left\{P_{2} G-\left(1-P_{2}\right)(1-\beta) W-b-\gamma\right\}>0
$$

Also, the welfare comparison for each type of entrepreneur is shown below: $\hat{I}_{1}^{H}-\hat{I}_{1}=-P_{1}\left(\hat{r}_{1}^{H}-\hat{r}_{1}\right)>0$, 


$$
\hat{I}_{2}^{H}-\hat{I}_{2}=\left(\hat{\pi}_{2}^{H}-\hat{\pi}_{2}\right)\left[P_{2}(G+W)-b-W\right]>0
$$

Proposition 4. Loan guarantees targeting high-risk entrepreneurs will mitigate low-risk entrepreneurs' credit rationing and increase all entrepreneurs' welfare, as well as overall economic welfare.

From Figure 8, if government raises the proportion of loan guarantees, there will be further inward movement of line $B_{1}^{H}=0$ and high-risk borrowers' expected utility line $I_{1}^{H}$. The increase in high-risk borrowers' expected utility alleviates further their incentive compatibility constraint of not misrepresenting themselves. Banks are willing to further reduce the requirement of low-risk borrowers' collateral. Proposition 5 states the condition of loan guarantee size for high-risk borrowers such that collateral pledge for low-risk entrepreneurs no longer constitutes a binding constraint for them.

Proposition 5. If government guarantees a larger percent of loan payment for high-risk entrepreneurs, it may lessen the collateral requirement for low-risk borrowers, so that they no longer face a binding collateral constraint.

Proof. $\bar{C}_{2}^{H}-W<0$, if $L>\left\{\frac{\gamma P_{1} P_{2}}{\left.\left[P_{2}\left(1-P_{1}\right)\right]-\beta P_{1}\left(1-P_{2}\right)\right] W+\gamma P_{1}}-P_{1}\right\}\left(1-P_{1}\right)^{-1}$.

\section{Conclusions}

Are loan guarantees the welfare-improving policy to channel assistance to targeted classes of borrowers? Our analysis of a competitive credit market with asymmetric information indicates that the answer depends on at whom a loan guarantee program is targeted. The results of this paper suggest that government loan guarantees should target high-risk entrepreneurs. On the one hand, loan guarantees targeting high-risk entrepreneurs reduce a pledge of collateral in credit contracts, save social costs, and increase economic welfare. Under the circumstances that borrowers' insufficient wealth causes a binding collateral constraint, loan guarantees targeting high-risk entrepreneurs alleviate the problem of credit rationing, thus improving economic welfare.

Government loan guarantees targeting low-risk entrepreneurs are harmful to the overall economic welfare because they deteriorate asymmetric information that already exists in the credit market. Low-risk entrepreneurs must pledge more collateral to sort themselves out from high-risk entrepreneurs. Taking into account transaction costs of liquidating collateral, the placing of collateral is socially costly. Thus, loan guarantees targeting low-risk entrepreneurs result in putting up too much collateral at a cost of reducing overall economic welfare. On the contrary, loan guarantees targeting high-risk entrepreneurs are Pareto improving because they mitigate the incentive compatibility constraint, effectively reduce collateral pledge, and increase economic welfare.

When sufficient collateral is not always available, asymmetric information in the credit market leads to endogenously arising credit rationing. Loan guarantees targeting low-risk entrepreneurs worsen the problem of credit rationing, whereas loan guarantees targeting high-risk entrepreneurs can alleviate it. The subsidy to high-risk borrowers decreases the incentive for misrepresentation of the type, which, in turn, reduces the need for banks to utilize credit rationing as a sorting device. Our findings suggest that well-intended efforts to "target" assistance to those denied credit may not be desirable on overall economic welfare grounds.

Our findings support the rationale for loan guarantees that a loan guarantee can lower the amount of collateral; furthermore, its target at riskier borrowers is in fact a welfare-improving mechanism. Loan guarantee schemes around the world differ in their design and the choices of the design can be crucial to the success and financial sustainability of these schemes [25]. Since loan guarantees have significantly expanded in the aftermath of the global financial crisis, their financial sustainability attracts more attention. It deserves a future study of the evaluation of the design of loan guarantees taking into account their financial sustainability. 
Author Contributions: Conceptualization, Y.-L.W.; Methodology, Y.-L.W. and C.-H.L.; Formal analysis, Y.-L.W. and C.-H.L.; Investigation, C.-H.L.; Writing-original draft preparation, Y.-L.W. and C.-H.L.; Writing-review and editing, C.-H.L. and P.-S.K.; Supervision, Y.-L.W.; Funding acquisition, Y.-L.W., C.-H.L. and P.-S.K. All authors have read and agreed to the published version of the manuscript.

Funding: This research was funded by Ministry of Science and Technology (Taiwan), R.O.C. (NSC 100-2410-H-194-062).

Acknowledgments: We would like to thank Jen-yao Lee and two anonymous referees for their useful comments and constructive suggestions.

Conflicts of Interest: The authors declare no conflict of interest.

\section{References}

1. Bester, H. Screening versus Rationing in Credit Markets with Imperfect Information. Am. Econ. Rev. 1985, 75, 850-855.

2. Bester, H. The Role of Collateral in Credit Markets with Imperfect Information. Eur. Econ. Rev. 1987, 31, 887-899. [CrossRef]

3. Besanko, D.; Thakor, A.V. Collateral and Rationing: Sorting Equilibria in Monopolistic and Competitive Credit Markets. Int. Econ. Rev. 1987, 28, 671-689. [CrossRef]

4. Grimsby, G. Partly Risky, Partly Solid-Performance Study of Public Innovation Loans. Res. Policy 2018, 47, 1344-1365. [CrossRef]

5. De Blasio, G.; de Mitri, S.; D’Ignazio, A.; Russo, P.F. Public Guarantees to SME Borrowing. A RDD Evaluation. J. Bank. Financ. 2018, 96, 73-86. [CrossRef]

6. Kim, J.; Wang, Y. Macroeconomic and Distributional Effects of Mortgage Guarantee Programs for the Poor. J. Econ. Dyn. Control 2018, 87, 124-151. [CrossRef]

7. Briozzo, A.; Cardone-Riportella, C. Spanish SMEs' Subsidized and Guaranteed Credit during Economic Crisis: A Regional Perspective. Reg. Stud. 2016, 50, 496-512. [CrossRef]

8. Riding, A.; Madill, J.; Haines, G., Jr. Incrementality of SME Loan Guarantees. Small Bus. Econ. 2007, 29, 47-61. [CrossRef]

9. Calcagnini, G.; Farabullini, F.; Giombini, G. The Impact of Guarantees on Bank Loan Interest Rates. Appl. Financ. Econ. 2014, 24, 397-412. [CrossRef]

10. Pergelova, A.; Angulo-Ruiz, F. The Impact of Government Financial Support on the Performance of New Firms: The Role of Competitive Advantage as an Intermediate Outcome. Entrep. Reg. Dev. 2014, 26, 663-705. [CrossRef]

11. Rothschild, M.; Stiglitz, J. Equilibrium in Competitive Insurance Markets: An Essay on the Economics of Imperfect Information. Q. J. Econ. 1976, 90, 629-649. [CrossRef]

12. Wilson, C. A model of insurance markets with incomplete information. J. Econ. Theory 1977, 16, $167-207$. [CrossRef]

13. Wang, Y. Does Collateral Cause Inefficient Resource Allocation? J. Econ. Bus. 2010, 62, 220-233. [CrossRef]

14. Best, R.; Zhang, H. Alternative Information Sources and the Information Content of Bank Loans. J. Financ. 1993, 48, 1507-1522. [CrossRef]

15. Hyytinen, A.; Väänänen, L. Where Do Financial Constraints Originate from? An Empirical Analysis of Adverse Selection and Moral Hazard in Capital Markets. Small Bus. Econ. 2006, 27, 323-348. [CrossRef]

16. Berndt, A.; Gupta, A. Moral Hazard and Adverse Selection in the Originate-to-Distribute Model of Bank Credit. J. Monet. Econ. 2009, 56, 725-743. [CrossRef]

17. Ivashina, V. Asymmetric Information Effects on Loan Spreads. J. Financ. Econ. 2009, 92, 300-319. [CrossRef]

18. Jarrow, R. The Economics of Credit Default Swaps. Annu. Rev. Financ. Econ. 2011, 3, 235-257. [CrossRef]

19. Smith, B.D.; Stutzer, M.J. Credit Rationing and Government Loan Programs: A Welfare Analysis. Areuea J. 1989, 17, 177-193. [CrossRef]

20. Li, W. Government Loan, Guarantee and Grant Programs: An Evaluation. Fed. Reserve Bank Richmond Econ. Q. 1998, 84, 25-51.

21. Li, W. Entrepreneurship and Government Subsidies: A General Equilibrium Analysis. J. Econ. Dyn. Control 2002, 26, 1815-1844. [CrossRef]

22. Chen, Y. Collateral, Loan Guarantees and the Lenders' Incentives to Resolve Financial Distress. Q. Rev. Econ. Financ. 2006, 46, 1-15. [CrossRef] 
23. Rai, D. Credit Rationing, Government Credit Programs and Co-financing. J. Appl. Econ. 2007, 10, 361-389. [CrossRef]

24. Minelli, E.; Modica, S. Credit Market Failures and Policy. J. Public Econ. Theory 2009, 11, 363-382. [CrossRef]

25. Gozzi, J.C.; Schmukler, S. Public Credit Guarantees and Access to Finance; Warwick Economics Research Paper; Department of Economics, University of Warwick: Coventry, UK, 2016. 